\title{
MACROLIDE RESISTANT PERTUSSIS IN AN INFANT WHOSE MOTHER WAS NOT VACCINATED AGAINST PERTUSSIS
}

P.Krol ${ }^{1}$, O.Thomas ${ }^{2}$, C.Webb ${ }^{1}$, U.Tinghäll Nilsson ${ }^{1}$, L.Lindberg' ${ }^{2}$, P.Nilsson Wimar ${ }^{1}$, U.Tedgård ${ }^{3}$

1 Skåne University Hospital, Dept. Of Paediatrics and Adolescent Medicine, Lund, Sweden, 2 Skåne University Hospital, Dept. Of Paediatric Anaesthesia and Intensive Care, Lund, Sweden, 3 Skåne University Hospital,Dept. Of Paediatric Haematology and Oncology, Lund, Sweden

\section{CASE REPORT}

a 6 week-old boy admitted to local hospital

nitial symptoms of cough, problems with eating and fatigue

mother with similar symptoms - not vaccinated in childhood

diagnosis of pertussis 1 week after initial symptoms 10-day course of erythromycin

admitted to PICU and intubated due to respiratory collapse 4 days after finishing antibiotic-course

continues with erythromycin+cefotaxime initially day 3 on PICU deterioration with tachycardia, dyspnea, leukocytosis and elevated CRP (Graph 1 and 2)

2 blood exchange transfusions on day 3 and 4 due to extreme leukocytosis. Good effect (see Graph 1) slow clinical/laboratory improvement from day 7

\section{INVESTIGATIONS}

laboratory tests (Graph 1 and 2)

microbology - B.Pertussis DNA in

secretions/expectorate

other bacterial, viral and fungal tests

negative

serology - B pertussis toxin IgG, lgA positive

immunology tests - IL-6 217ng/L (<8ng/L),

immunoglobulins and lymfocyte subclasses normal

chest X-ray - bilateral pneumonia with atelectasis echocardiogram - signs of pulmonary hypertension

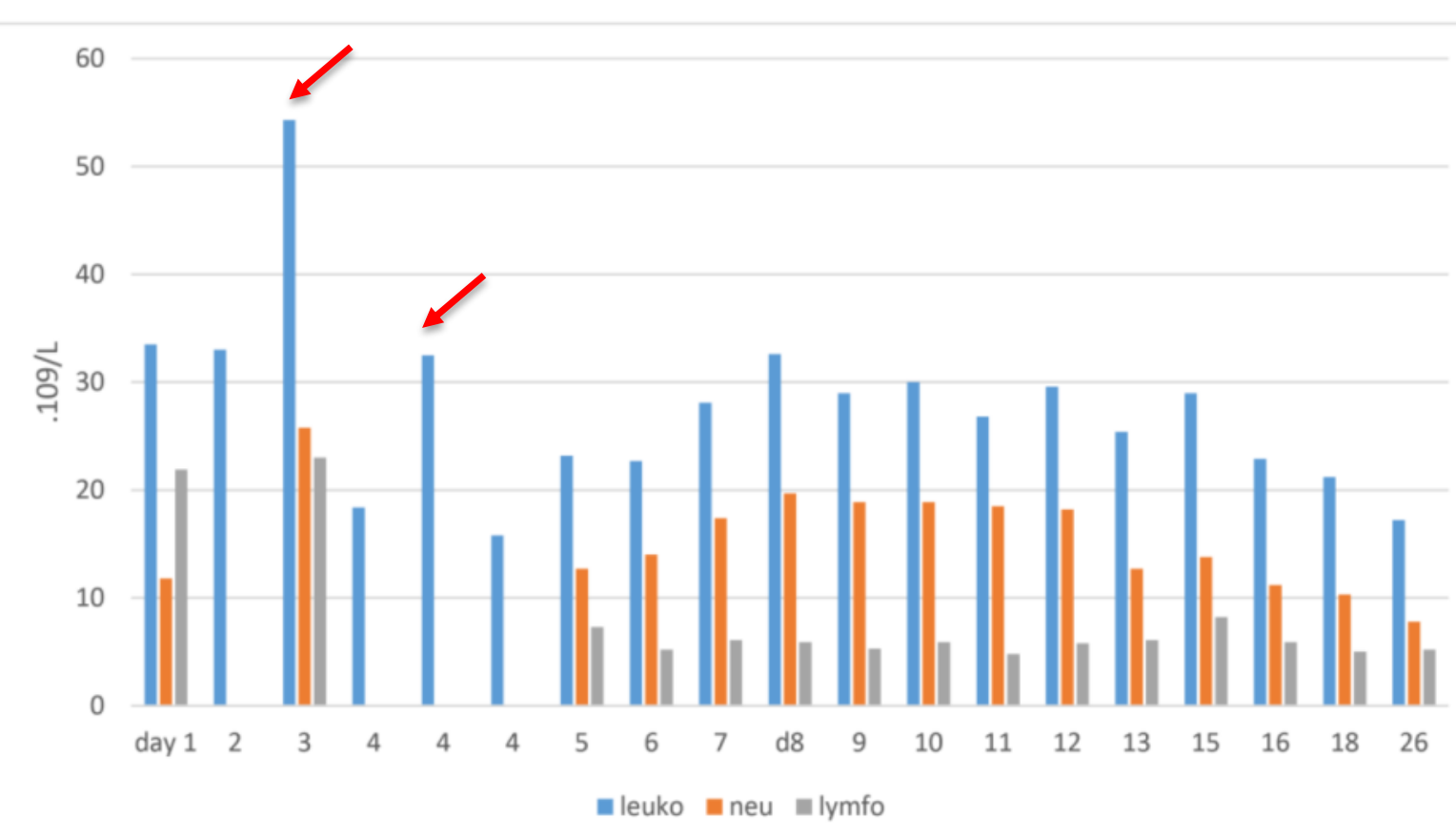

Graph 1. Trend of leukocytes during infection. Labeled points

show when patient received blood exchange transfusion.

$$
\mathrm{CRP}(\mathrm{mg} / \mathrm{L})
$$

250

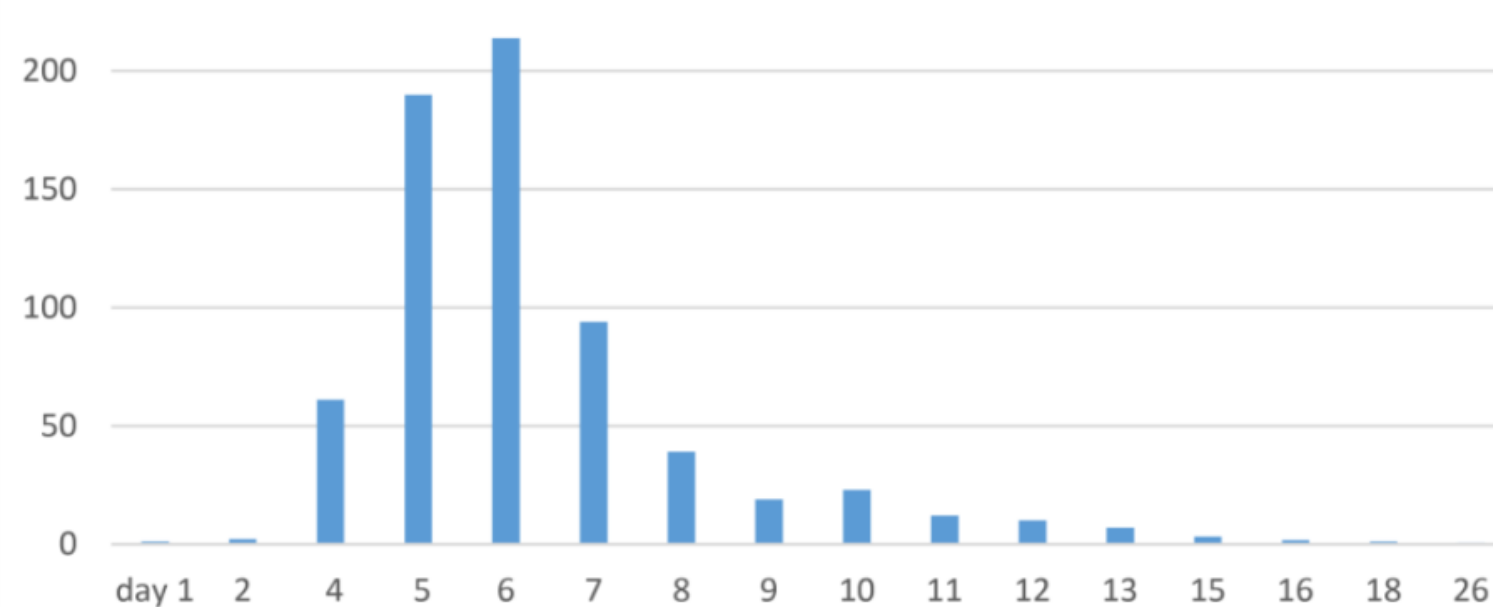

Graph 2. CRP levels during infection days after transfer to PICU.

\section{TREATMENT}

23 days of antibiotic treatment (erythromycin, cefotaxime, azithromycin, meropenem, trimetoprim-sulfomethoxazol)

2 blood exchange transfusions due to leukocytosis

1 dose of intravenous immunoglobulin $(1 \mathrm{~g} / \mathrm{kg})$

16 days of mechanical ventilation

11 days high-flow nasal therapy (Optiflow)

\section{WHY DID INITIAL TREATMENT FAIL?}

1) Secondary infection? All cultures negative

2) Test for antibiotic resistance? POSITIVE (Table 1)

Mutation A2037G

MACROLIDE-RESISTANT Bordetella pertussis source: K Tegmark Wisell et al., The Public Health Agency of Sweden)

Klaritromycin: >256 g/mL

Erytromycin: $>256 \mathrm{~g} / \mathrm{mL}$

Azithromycin: $>256 \mathrm{~g} / \mathrm{mL}$

Trim-sulfa: $0.064 \mathrm{~g} / \mathrm{mL}$

Ciprofloxacin: $1 \mathrm{~g} / \mathrm{mL}$

Table 1. Minimal inhibition concentration (MIC) for antibiotics.

\section{DISCUSSION}

1) The vaccination of pregnant women can significantly decrease the risk of pertussis infection in neonates and infants (1)

2) Usual treatment with antibiotics can fail due to bacterial resistance (2)

3) Other treatment modalities in severe cases of pertussis infection with complications (3) 